\title{
Interpersonal and Intersubjective Alienation in Social Stigmatization and Depression
}

\author{
Asena Paskaleva-Yankova \\ Institute III, Philosophy, Faculty of Human Sciences, Otto-von-Guericke-Universität Magdeburg, \\ Magdeburg, Germany
}

\section{Keywords}

Social stigmatization - Relational affect · Alienation .

Depression · Loss of intersubjectivity

\begin{abstract}
The subjective experience of social stigma has been widely researched in terms of discrimination, rejection, isolation, etc. These are commonly understood within the traditional individualistic framework of affective experience and sociality, which fails to address the transformative effects of social stigma on how one experiences the social realm and the own self in general. Phenomenology and recent work on the relationality of affective experience acknowledge the central role interpersonal interactions play in subjectivity and offer a suitable approach towards addressing the complexity of the subjective experience of social stigma. Focussing on autobiographical accounts, I propose that the experience of social stigmatization is characterized by an affective atmosphere of interpersonal alienation. Its counterpart, an atmosphere of belonging, is closely related to social empathy, which is eroded by prejudicial attitudes and stereotypes. The breakdown of social empathy establishes a peculiar form of relationless relationality that radically transforms one's sub-
\end{abstract}

karger@karger.com www.karger.com/psp

Karger"

BOPEN ACCESS
(C) 2021 The Author(s)

Published by S. Karger AG, Basel

This article is licensed under the Creative Commons Attribution 4.0 International License (CC BY) (http://www.karger.com/Services/ OpenAccessLicense). Usage, derivative works and distribution are permitted provided that proper credit is given to the author and the original publisher. jectivity. The transformation of subjectivity is structurally similar to disturbances of intersubjectivity in psychopathological conditions such as depression and feelings of disconnectedness, loneliness, and even shame are common in both cases.

(C) 2021 The Author(s)

Published by S. Karger AG, Basel

\section{Introduction}

Erving Goffman [1] defines stigma as "an attribute that is deeply discrediting" [p. 1] and indicative of "undesired differentness" [p. 15]. It is associated with a range of discriminatory practices, tendencies towards avoidance, feelings of shame, and isolation. Traditional research on social stigmatization has operated within an individualistic framework when studying its impacts: For instance, the social aspects of stigma are viewed as environmental stimuli that its victims appraise and respond to [2]. Even when viewing stigmatization as a social phenomenon [2], the complex dynamics of interpersonal interactions and its impacts on subjective experience at a fundamental bodily affective level are neglected. Although social stigma has frequently been considered a social construction 
and thereby a relational phenomenon, research has failed to address the relationality of its experiential aspect. Traditional models of social stigmatization focus on processes of cognitive categorization or application of socially and culturally shared stereotypes and prejudicial attitudes towards individuals or groups [3-5]. They study their impact on one's social identity, its integrity, and one's self-esteem, academic achievement, and mental and physical health (e.g., [6]). For instance, Bruce Link et al. [7] have examined the negative effects of the social stigmatization of mental illness on self-esteem, and Fred Markovitz [8] has focused on how it impacts psychological well-being. While these are undoubtedly aspects of crucial importance, the focus on reflective processes of categorization, labelling, and their impact on self-understanding and well-being excludes a first-personal perspective on experience and does not reflect the central role of interpersonal interactions in subjective experience. Adopting a phenomenologically inspired relational perspective on social stigmatization can account for the role of both reflective processes and constructs, such as stereotypes and the typified perception of others and prereflective interactional dynamics. The latter gives rise to atmospheric experiences of alienation that are peculiar to social situations. This atmosphere of interpersonal alienation will be compared and contrasted with a more fundamental pathological intersubjective alienation characteristic of depression. While the interpersonal alienation of social stigmatization operates at the level of social interactions and practices and impacts experience at a personal level, intersubjective alienation in depression involves more fundamental transformations of how others are experienced and engaged with. The two forms of alienation, nevertheless, share substantial similarities in both qualitative and structural respects that pertain to the essentially relational nature of human subjectivity.

\section{Interpersonal Alienation in Social Stigmatization}

Victims of social stigma are subjected to discrimination, verbal and physical aggression, being ridiculed, and the like. Feelings of shame, loneliness and alienation, not belonging, or being excluded from society are commonplace. In examining the complex experiential phenomenon of being subjected to social stigmatization, I am going to propose that it operates both at a reflective level of stereotypes, evaluations, and patterns of meaning and at a bodily affective level of pre-reflective subjectivity. Stereotypes, for instance, drive processes of typification that disrupt the empathetic engagement with others. This establishes a peculiar relational pattern, which in virtue of its interactional dynamics can affect different aspects of subjective experience in a synchronic and a diachronic dimension.

Social stigma centres around negatively evaluated characteristics such as racial and cultural identities, socioeconomic status, sexual orientation, various personal attributes like physical appearance and age, and mental and physical illnesses $[9,10]$. These characteristics are termed undesired, are disvalued, and present those bearing them as different. As such, each of them is associated with a wide range of more or less specific negative stereotypes, attitudes, sets of values and meanings. Aiming at a comprehensive account of social stigmatization, I examined first-person accounts of being subjected to social stigma due to disability, a chronic mental or physical condition, sexual orientation ([11] includes first-person accounts focussing on various stigmatized attributes), physical disability [12], and race [13]. Their authors emphasize that others commonly perceive them in a particular manner related to stereotypes associated with the characteristics setting them apart. Julie Lythcott-Haims recollects how their neighbours' daughter perceived her father.

She [the neighbours' daughter] saw your dad [Lythcott-Haims' father] across the street on his riding lawn mower and said, "Oooh look, they have a Black gardener." [...] Daddy loves riding that mower, I thought to myself. [...] He's so proud to have all of this land, these lawns, so excited to think ahead to next spring's gardens. [...] Our house was bigger than the Sullivans'. My father was the fucking former Assistant Surgeon General of the God Damn United States. [13, p. 22; 12, 14, 15 describe similar experiences]

Typification, exemplified by this passage, is an integral part of how we encounter others in social settings. According to Alfred Schütz [16], "it involves the recognition and grasping of an 'objective web of meanings,' practices, or social facts in which subjects are always already embedded" [p. 94]. When perceiving the world, we encounter objects in terms of the knowledge we have of them - during our walk in the park, we perceive trees, flowers, and birds. Depending on our knowledge, the individual trees can be recognized and perceived as elms or beeches and the different flowers can be roses or daisies. This also pertains to other people who we may know or may not know. Even when we have had no experience with someone we meet on the train or on our way to work, we typify them, that is, we encounter them as a member of a social or a cultural group that has specific characteristics and is embedded in a particular web of meanings, values, practices, 
and social facts. We also perceive their actions, behaviours, personalities, and motives in a specific manner, so that, for example, one and the same action performed by individuals belonging to different types can be a welcoming or a threatening gesture in one and the same situation. Typification can occur at various levels, and when encountering others, we commonly choose one of these. When posting a letter, I typify the postman only in terms of their occupation and not in terms of their personality. We also commonly do not reflect on the ways we encounter and understand our environment in terms of typification until we can reach our aims and fulfil our goals [17]. In cases in which our actions guided by typification are not successful, we can revise this taken for granted practical knowledge. This knowledge about what is to be done and what is normal is a social construction, it is socially distributed, and one acquires it when learning a language, in one's family, when interacting with others, and through generational transmission [17]. Typification, moreover, is habitual, and we engage in it automatically when perceiving an object or an individual [18]. Our perception of others in face-to-face encounters thus always starts off from a particular general or type perspective $[16,19]$ that determines how we encounter them and how we engage with them.

In the case of social stigmatization, the web of objective meaning or practical knowledge associated with the attribute driving the typification is characterized by stereotypes that can associate it with, for instance, assumptions and evaluations of one's personality, actions, or even professional occupation, as in the passage quoted above. While the stereotypes related to social stigma can vary, what they have in common is that they present the victim of social stigmatization as the "discounted," "tainted," "deficient" other and aim at their exclusion from social community. According to Goffman, one of the central characteristics of stigma is that those bearing it are "somehow not human" [1, p. 15]. In his recent work on exclusion and dissociation of empathy, Thomas Fuchs proposes that cases of dehumanization can be understood as disturbances of extended or social empathy based on failures of recognition. Building on primary empathy, which is the "direct embodied perception of another's expressive behaviour, implying one's own bodily resonance and one's spontaneous feelings" [20, p. 2], social empathy crucially involves the notion of recognizing the other as the other of myself, a person like me with a subjective perspective, values, rights, and commitments that I, as a person and moral agent myself have to answer. Fuchs' [20] analysis focuses on dehumanization in the case of what can be considered radical dissociations of empathy exemplified by Nazi perpetrators who were devoted and caring family members and at the same time were able to commit utter atrocities towards Jews. In social stigmatization, the dissociation of social empathy similarly goes along with a form of dehumanization that in most cases limits or completely strips the status of moral agents of those bearing the stigmatized attribute. While this might not in all cases go along with the kind of atrocities that Fuchs deals with, failing to recognize one as a moral agent can come in the form of restricting the range of rights and social practises they have access to as described by Britney Wilson and Stephen Kuusisto:

[The concept of entitlement is] the idea that we are acting as if someone owes us something rather than merely asking to be treated with the respect and human dignity we deserve. It is the belief that people of a certain status or apparent condition have no right to demand better because we should just be happy with whatever we get. We should be happy we have anything at all. [21, p. $210 ; 13,22,23$ provide similar reports]

[...] my father tries to buy a life insurance policy in my name, only to find that blindness is an impediment. That same year my mother decides to enrol me in public school instead of an institution for the blind and finds both consternation and disapproval from staff and school officials. [12, p. 13; see also 22, $24,25]$

The failure of recognition in the form of denial of rights and limiting one's access to social practices excludes one from a community of subjects who share views, values, and commitments, or in other words encounter each other within a second-person perspective of a social we. The second-person perspective, according to Fuchs, is "the intersubjective, participant or co-experiencing perspective, referring to situations of reciprocal interaction that are characterized by some form of mutual relatedness and coupling of the partners" [26, p. 658]. Within a shared second-person perspective, others are encountered as co-creators of the patterns of meaning in the world. In terms of the interaction, one is engaged in and with respect to the particular pragmatic context, for instance, various entities acquire shared significance and meaning. In contrast, the first- and third-person perspectives are the isolated stances of, respectively, individual subjective experience and detached observation.

In everyday life, we constantly engage in reciprocal face-to-face interactions within a second-person perspective, in which we share practical meaning with the other and address them as a social you of equal moral standing. These include interactions in various settings as on the 
train, when one meets the other's gaze and reciprocates it, smiles, nods, or simply acknowledges their existence, and more specific ones as when one offers their seat on the bus to an elderly lady. A second-person perspective can, in at least some cases, be closely tied to a range of emotions and attitudes, such as respect and concern for others. Failing to recognize the other as a moral counterpart of myself, I also fail to respect their needs and wishes, so that I, at least to some extent, fail to enter a context of shared meaning. What is of highest importance to them not only seems of no relevance but also, I might not be able to imagine it being of any significance so that I might not be able to put myself in their shoes. Consequently, lacking a respectful attitude towards others as when failing to recognize them as moral agents, I may be confined to the role of passive and disengaged spectator who also fails to appreciate what is of value and meaning to them. An essential component of a second-person perspective thus is a shared evaluative perspective that presents various aspects of the world in general and specific situations in particular as significant. Even when the patterns of higher level significance of the interactional partners vary, an attitude of respect enables the interactional partners to acknowledge these differences and be able to perceive a particular situation in a manner that corresponds to that of the respective interactional counterpart. The differences in evaluative perspectives should also not be too grave as differences pertaining to, for example, basic rights cannot be abolished. In addition, it is, of course, not possible that all differences in evaluative perspectives disappear, so that the other's perspective is experienced as one's own.

It has been suggested that the second-person perspective is essential to the experience of group membership. Building on Edmund Husserl's views on intersubjectivity, Dan Zahavi [27] proposes that a basic requirement for coming to identify with certain groups and social communities and experience oneself as belonging to these is that one encounters and engages with others within a second-person perspective. Necessary for belonging is, according to him, that (1) differences between oneself and others are not completely abolished; (2) these differences, though, are not too salient; and (3) one becomes somewhat alienated from oneself by experiencing oneself through the eyes of the other.

Engaging the other in a second-person perspective can be precluded by stereotypes and negative attitudes. These are commonly habitual or taken for granted and build the basis for processes of typification. Centring around the dehumanization or denial of the status of a moral agent of the stigmatized other, they preclude one from adopting a second-person perspective as they present the other not as a respect-deserving member of a community of moral agents, but as essentially different from one, as espousing a radically different evaluative perspective. First-person accounts, for instance, frequently include descriptions that present significant discrepancies in the evaluative perspectives of stigmatizers and the victims of social stigma:

[Peter] Singer is easy to talk to, good company. Too bad he sees lives like mine as avoidable mistakes. [14, p. 20; 12, 14, 15, 19, 28-30 also report of similar experiences]

The differences between the evaluative and normative significance associated with physical disability, the stigmatized attribute, are in stark contrast and are too salient. The "objective" web of meaning presents physical disability as negatively impacting the quality of life of people, as making a "normal" life impossible. Disability is something to be avoided as a good life is impossible for disabled people. This, though, is not the case for Harriet McBryde Johnson. Her perspective on her condition and her life does not merely differ from Peter Singer's, it is irreconcilable with it. This strips away a sort of common ground of shared meaning and significance that is essential to establishing a second-person perspective. Consequently, upon a disturbance of the second-person perspective, the individual suffering from a stigmatized condition becomes simply the other, not a social you with whom I share a meaningful context. Social stigmatization, at least in some cases, then presents us with a disturbance of a shared second-person perspective closely related to stereotypes and knowledge shared in social and cultural groups. Consequently, for those bearing the stigma, the social realm is not characterized by fundamental reciprocity and mutuality but by alienation - they are the social him or her encountered essentially as the bearer of a negative attribute, which can frequently be associated with experiences of shame as described in first-person accounts:

\footnotetext{
I grew up having every flaw pointed out to me. I grew up believing I was wrong. It's part of the territory that comes with being born with a facial disfigurement [...]. My eyes were too far apart, too crooked; my nose was too big. My jaw was too far back; my ears were too low. There were regular appointments with doctors and surgeons trying to fix me and my twin sister [...]. [15, p. 42; see also $12,13,29-33]$
}

The effects of social stigmatization on those subjected to it, though, extend well beyond instances of discrepancies of evaluative perspectives, feelings of shame, and the 
like. The exclusion from a second-perspective and dissociation of empathy that result from processes of typification also go along with specific relational patterns and interactional dynamics that shape all aspects of subjective experience. In what follows, I am going to present a relational view of affective experience and elaborate on how we can conceive of the impact of social stigmatization as a relational phenomenon.

\section{Relational Affect}

A relational view of affective experience starts off from a focus on the embeddedness of subjective experience in the complex patterns of interactions between persons, persons and their environment, persons and social structures and institutions, and persons and the arrangement of specific physical environments. Within this framework, affective phenomena "[...] are approached with a view to their embeddedness within ongoing complex situations in which various actors, objects, spaces, artefacts, technologies, and modes of interaction coalesce, all contributing to the particular character of the affective process in question. Thus, researchers might focus on interactive dynamics between persons, from basic forms of preconscious embodied coordination, synchrony, and affect attunement up to fully self-conscious forms of practical engagement" [34, p. 7]. Relational affect can be defined as being affected and affecting in a particular manner inherent in the interactive dynamics of specific situations. Examples of relational affect include affect at the workplace, where specific arrangement of physical artefacts, features of the environment, and technologies enthral the subject into particular affective patterns, a lively family dinner [35], sports, and entertainment events, political rallies, etc. The dynamics inherent in such so-called social domains of practice [35] impose specific affective patterns by means of introducing and entrenching evaluative and normative constellations. A family dinner at Christmas, for instance, goes along with relational patterns and interactional dynamics that differ from those of a gathering at the wake of a deceased relative. The interactional patterns and dynamics that go along with each of these domains of practice or situations at least in part constitute both the individual affective experience of those participating in them and the atmosphere associated with the occasion, such as the cheerful spirit of the family dinner, or the air of mourning, respect, and mutual consolation, and feelings of grief and sadness at the wake.

Alienation in Social Stigmatization and Depression
A relational view on affect, therefore, conceives of affective experience as resulting from the "[...] interactive dynamic that for the most part inheres in social domains of practice" $[35$, p. 70$]$. The negative stereotypes and attitudes that accompany social stigmatization constitute its own domain of practice and these establish the dynamics of interactions between the counterparts by determining the specific affective relational patterns - such of exclusion of the stigmatized party, of judgement, discrimination, or even aggression and violence. As already mentioned in the previous section, victims of social stigmatization are, at a reflective level, dehumanized in various ways. At a pre-reflective level, the bodily affective dynamics of exclusion inherent in this relation of alienation shape the quality of subjective experience by establishing so-called affective atmospheres.

\section{Affective Atmospheres and Alienation}

Affective atmospheres, like those associated with a family Christmas dinner, or a wake, are diffuse, pre-reflective, and pre-conceptual (affectively charged) qualities that envelop us. They are "what is in the air," when we enter a building, or join a social gathering, etc. In contrast to emotions or moods, affective atmospheres are not distinct or discrete states that we reflect upon. Rather, they are first and foremost that which is pre-reflectively experienced as filling the lived space. As suggested by Ben Anderson, affective atmospheres are "singular affective qualities that emanate from but exceed the assembling of bodies" [36, p. 80] and are thus essentially relational phenomena realized in a distributed manner by several elements spread across a scenery [37, p. 43].

Common in everyday life, especially in interpersonal interactions in the social domain, is an atmosphere of belonging to a community of moral agents. In most of the cases, when we engage with someone in specific situations, a tacit background feeling of confronting an interactional partner of equal standing is always already present. When, in the course of the interaction, we are addressed as a social you, an atmosphere of reciprocity and mutuality is established. At a pre-reflective level, this is established by a reciprocation of gaze and gestures and affect attunement that accompany a shared second-person perspective. A shared second-person perspective, thus, is associated with processes of recognition at a reflective level and affective bodily resonance at a pre-reflective level.

An affective atmosphere of interpersonal alienation can arise from the dynamics of dissonance and discord of evaluative patterns, avoidance, limitations of access to so-

Psychopathology 2022;55:201-210 
cial practices, etc., described in the previous section. At a reflective conceptual level, there is a dissonance of patterns of meaning and significance, which establishes a relationship of alienation or loss of relatedness. This relationship is characterized by interactional dynamics of discordance and dissonance such as excluding one from various practices, denying one particular rights at a conceptual reflective level. These can be mirrored, at a bodily affective level, by pre-reflective practices of gaze aversion, staring, physically withdrawing, etc., and culminate in experiences of failing to relate with others or of being alienated and excluded from shared space at a fundamental bodily level, as described here:

What I hadn't counted on was how differently I'd be treated with these braids. I take the same bus and subway lines [...]. Go to the same grocery store and restaurants. But some white strangers now glance warily at me on the sidewalk, pull their bodies and arms away from me and into themselves as I walk past. At the Star Market, a white mother looks over at me and then puts a protective arm around her child while keeping her eyes on me. [13, p. 106; see also 13,14$]$

The pre-reflective lack of reciprocity and mutuality place those subjected to social stigmatization in the position of a detached third-personal presence. These dynamics are experienced in terms of a diffuse, yet perceptible sense of not being part of a shared social realm, as others fail to affectively resonate with one even at this bodily affective level. Thereby, one is, in addition to being typified and precluded from engaging in a shared second-person perspective, excluded from a shared bodily affective space.

This is an instance of what we can understand as a synchronic affective atmosphere - one arising from an ongoing interpersonal interaction. Relational affect also possesses a diachronic dimension originating from recurring relational patterns, dispositions, and emotion repertoires. A recurring pattern of relationless relationality or alienation characteristic of cases of social stigmatization can become habituated and sediment into an affective and relational repertoire, which is associated with social domains and occasions. Thus, even in the absence of ongoing face-to-face interactions, a social gathering or event might be encountered as bearing an atmosphere of alienation or lack of relatedness even without a reflective realization of the potentiality of engaging in a stigma-driven interaction. On the part of the bearer of the stigma, it can be experienced as a diffuse, yet perceptible sense of dissonance between them and the mutuality shared by a chattering crowd at a party.
The atmosphere of interpersonal alienation in cases of social stigmatization presents us with a somewhat peculiar case of atmospheric experience: (1) based on a missing or lost relationship of relatedness, it is not an atmosphere that consolidates or is experienced as establishing an affective unity; (2) it is also not an atmosphere of mutual resonance, but rather of lack of such; and (3) may extend beyond instances of face-to-face interpersonal interactions as, for example, in cases when one anticipates or envisions such. With respect to (1) and (2), one might argue that the failure to consolidate the interacting partners and the lack of bodily and affective resonance resulting from processes of typification and failures of recognition, render alienation a relational phenomenon more akin to existential feelings than to affective atmospheres. I wish to claim, though, that it is highly situational character and it is grounding in the interactive dynamics inherent in various domains of practice and situations do not grant it the status of a fundamental background orientation or a feeling of being, that is, the background to our even most basic sense of reality. Affective atmospheres, unlike other pre-reflective background structures that shape affective experiences, such as existential feelings $[38,39]$ are rather situation-bound and pertain to either ongoing or anticipated situations and occasions. Existential feelings, in contrast, are feelings of being or finding oneself in the world that are not specific to situations or interactions as suggested by [40, 41].

In what follows, I am going to address another instance of experiences of alienation, namely, the experience of major depression. In depression, similarly to cases of social stigmatization, one feels alien, radically different from others, left out, lonely, and ashamed.

\section{Intersubjective Alienation in Depression}

A consistent theme in first-person testimonies of depression is that the world their authors find themselves in is not shared with other subjects. ${ }^{1}$ Autobiographical accounts describe experiences of profound isolation, a failure to relate and feel related to others, and feelings of loneliness and shame. I am going to suggest that depression is characterized by intersubjective alienation (see

\footnotetext{
The experience of depression has been analysed by Fuchs [42] in terms of bodily and affective aspects of disruptions of the experience of and interactions with others. While these are central to understanding depression, in this paper, they will not be discussed as it is above its scope to offer a comprehensive account of disturbances of intersubjective experience in depression.
} 
[43] for a detailed account of intersubjective alienation in terms of disturbed fundamental intersubjectivity based on first-person reports), which exhibits significant similarities with the atmosphere of interpersonal alienation of social stigmatization. Intersubjective alienation is also an instance or relational affect, which, though, is constituted by a more fundamental, pre-reflective relatedness, respectively, the loss of such.

Direct interactions with others, as discussed in the previous section, shape our subjective experience. As suggested by Hendrik van den Berg [44], radical changes in experiencing and interacting with others are at the core of psychopathology in general. In non-pathological cases, we encounter the world against a background of what we can call "fundamental intersubjectivity," a basic relatedness to others in terms of the shared second-person perspective introduced earlier. It can be shattered when encountering a radically different and potentially irreconcilable foreign perspective, similarly to instances of social stigmatization. Sharing a subjective perspective with others or being able to adopt a shared perspective with regard to at least some fundamental aspects of reality is made possible by the faculties of primary, secondary, and tertiary intersubjectivity, which have gained significant attention in social cognition research [45-50].

At an initial stage of primary intersubjectivity as suggested by Trevarthen, infants start perceiving the intentions of others with the help of embodied sensory-motor capabilities like gaze-following, perception of goal-related movements, of meaning and emotion in movement, and bodily posture [46]. Around the age of 1 year, infants start developing secondary intersubjectivity, which makes it possible for them to perceive others as intentional agents performing purposeful actions [46]. By expanding intersubjective interactions and including objects in them, infants come to enter the realm of shared meaning in particular in pragmatic contexts [46, 49]. Additionally, tertiary intersubjectivity enables the anticipation and detection of potential individual differences across individual subjective perspectives and thereby makes a transition between a first-person I, a third-person he or she, and second-person you or we possible. Narrative competence also plays a crucial role here as exposure to stories or narratives introduces other subjects with their respective perspectives and how these relate to their experiences and actions [49]. Within a shared second-person perspective established on the basis of perceiving others as intentional agents, engaging in the co-creation of patterns of meaning, and the ability to switch between different perspec-

Alienation in Social Stigmatization and Depression tives, the other is encountered as sharing at least some patterns of significance.

In non-pathological cases, we commonly encounter others within a shared yet to some respect individual subjectivity within a shared second-person perspective. For instance, fundamental patterns of significance and meaning concerning the experience of reality, at least some basic affective evaluations of fundamental aspects of life can be shared among individuals. More specific, contextbound affective responses can vary individually. An instance for the former would be the common significance attributed to life as generally meaningful, despite adverse times, a hopeful anticipation of future prospects. Individual patterns of significance of more specific aspects or situations can vary, so that, for example, time spent with one's family can be viewed differently, changes in life can be appraised in different ways by different people. Fundamental intersubjectivity can be understood as the result of (1) experiencing others as intentional agents endowed with a subjective perspective; (2) an experience of other actions as meaningful, goal-directed, etc., in virtue of the participation in intersubjective interactions in shared pragmatic contexts; and finally (3) the ability to switch between a first-, second-, and third-person perspective, which enables tacit self-awareness and the anticipation of potential individual differences in subjective perspectives. Thereby, we encounter others as bearers of an individual subjective perspective, which, though, is at least in some fundamental aspects shared with one's own especially within the second-person perspective of interacting with each other.

\section{Loneliness and Shame in Depression}

Individuals suffering from depression consistently describe experiencing the world in a markedly different way during episodes of the illness. It is a world of torment and suffering, it is threatening and oppressive, and lacks possibilities for change or hope. Others seem as if inhabiting a different world, one which is not only doom, gloom, fear, and desperation. When attempting to engage with them, share, or sustain an existing relation, individuals suffering from depression seem to experience a radical disruption of the shared second-person perspective. What affects others and how they find themselves in the world seem incomprehensible for those in the deep throes of a depressive episode. It is impossible to maintain or establish patterns of shared meaning, so that one feels utterly lonely and disconnected: 
At every party, every bar I would sit or stand like a block of wood, petrified, a morose, and befuddled spectator surrounded by care-free merrymakers who seemed like a completely different species [...] than my mouse-like self. [51, p. 234; 52-56 also report of similar experiences]

This loss of a shared significance goes along with a tendency to avoid others and to actively seek out isolation. As others appear radically different from one, any and each attempt to engage in interactions adds to the burden of suffering. Accordingly, a very common aspect of depressive experience is the withdrawal from and avoidance of social interactions and exemplified by the following passage:

The last time I'd tried to attend a party [...] I'd gone stiff immediately upon entering the house and walked right back without speaking. [57, p. 146; see also 55, 58].

Resulting from this, the world of the individual suffering from depression is one of profound loneliness, selfimposed, and even sought-after isolation. One fails to relate to and feel related to others.

Upon (1) this breakdown of a shared subjective perspective, one is confined to a solitary first-person perspective of detached observation and isolation. From this perspective, one may lose the sense of tacit self-awareness established by the embeddedness in interactions with others as it can be replaced by an acute awareness of (2) being an isolated entity. From this position of isolation and disembeddedness, the other can also be experienced only by means of detached observation. Consequently, (3) at least in some particular situations, one may feel encountered by the other as a detached entity, that is, the bearer of specific characteristics. This foreign third-personal perspective replaces the tacit second-personal self-awareness of embeddedness in a shared world and becomes (4) a peculiar form of experiencing oneself. This peculiar form of self-awareness in terms of being the object of observation can be painfully experienced as being encountered by others as a deficient, failing self, and the bearer of negative characteristics. It is important to note that only certain situations and contexts, commonly those involving standards or norms of performances such as social roles, professional settings, and interpersonal relationships are more strongly related to experiences of shame and embarrassment. In these, the peculiar form of self-awareness, coupled with one's abilities and characteristics gives rise to feelings of shame as, for instance, described here:

There is an enormous amount of self-criticism, self-loathing, and low self-esteem. Everything revolves around the percep- tion of self. Most depressives find themselves - as much to their own disgust as to everybody else's - annoyingly and negatively self-obsessed. [53, p. 31; 52, 55-60 also report of similar experiences]

Shame, it has been suggested, is a self-conscious emotion whose object is the own self as experienced by others [48]. Depressive shame, thus, can be understood as the direct result of the loss of interpersonal embeddedness, which confines one to the perspective of observing and being observed. One's common tacit self-awareness of being the active participant in an intersubjectively shared world shifts to an experience of oneself as a disembedded bearer of negative characteristics and qualities.

\section{Interpersonal and Intersubjective Alienation}

From a relational perspective of affect, social stigmatization can be viewed as a radical disturbance of relatedness resulting in an affective atmosphere of interpersonal alienation. The experience of alienation and disconnectedness in depression is associated with the loss of a more fundamental sense of relatedness and belonging. The clash of subjective perspectives at the level of "objective" and subjective or personal meaning of a certain condition or attribute is undoubtedly of higher cognitive complexity and is embedded in a network of further patterns of social, cultural, and political meanings that usually are habitual and govern how we perceive and interact with others.

The atmosphere of interpersonal alienation differs from the sense of intersubjective alienation in depression also in view of their respective sources. The former is grounded in the prejudicial, disrespectful, and aggressive attitude of others who (tacitly or implicitly) recognize one as the deficient other and exclude one from social community. Depressive alienation is not related to a (voluntary) reaction on the side of other people. It is inherent in a disorder of affect, which transforms how the world is experienced and as such not related to tacit or habitual knowledge that can be embodied at a pre-reflective level. The experience of social stigma thus may additionally be characterized by feelings of anger at being shunned by others, of resentment of being treated this way and active opposition to social stigmatization. The intersubjective alienation of depression can, in contrast, be accompanied by a sense of loneliness, of not being understood by others, of being confined to a world of solitary torment and suffering that, though, are rather passive.

Even in the face of these differences, interpersonal and intersubjective alienation have a common structure. In de- 
pression, the clash of meaning is at the level of basic significance, of patterns of significance that we commonly take for granted and shared with others. But being repeatedly subjected to patterns of "objective" meaning, which defies one's worth, the significance of one's existence, and one's basic rights, when fostered frequently across various contexts and in the long term can amount to a loss of shared fundamental significance. Whose life has more worth, what rights can one claim, how one is being addressed, glanced at, approached bodily, and the like place one in a world of alienation, hostility, threat, and lack of understanding. This resembles the perspective that the depressed individual fails to share with others who are still able to enjoy life (at least occasionally), to find meaning and hope in their existence, etc. The atmosphere of relationless relationality and alienation in social stigmatization is also a world of solitary confinement. Negative stereotypes that are closely linked to processes of typification, loss of empathy, and establishing an atmosphere of alienation, from a relational perspective on affect, are not merely stimuli that one responds to but rather constitute a higher level instance of loss of relatedness with others that can culminate in a loss of fundamental intersubjectivity and transform how one finds oneself in the world and experiences the own self. Like in cases of depression, one can become acutely and negatively aware of oneself, once a common subjective perspective has been lost as a consequence of the clash of higher order significance. The own self, then, becomes apparent in virtue of how it is encountered by others and the commonly shared stereotypes that drive processes of typification.

\section{Conclusion}

An examination of first-person accounts of social stigmatization and of depression highlights similarities between the two. These, most importantly, pertain to the structure and dynamics of the impact of interpersonal and intersubjective interactions and experiences: as in cases of depression, the atmosphere of interpersonal alienation resulting from social stigmatization is the direct result of a loss of shared second-person perspective. A failure to negotiate common patterns of significance confines one to a solitary perspective that can also impact tacit self-awareness. Against the background of the loss of basic relatedness, all aspects of one's subjective experience are severely affected, so that experience, action, and thought can be severely distorted. Rather than conceiving of the interpersonal isolation of social stigmatization as the result of the appraisal of negative stimuli related to stereotypes, a relational perspective both accommodates the centrality of intersubjective and interpersonal experience and illustrates the dynamical and structural changes in cases that are also characterized by a loss of relatedness to others such as depression.

\section{Acknowledgments}

I wish to thank the anonymous referee for their invaluable comments that enriched the paper.

\section{Conflict of Interest Statement}

The author has no conflict of interest to declare.

\section{Funding Sources}

The author has not received any external funding for this study.

\section{Author Contributions}

The author confirms sole responsibility for the conception and writting of all parts of the paper.

\section{References}

1 Goffman E. Stigma: notes on the management of spoiled identity. London: Penguin; 1963.

2 Yang LH, Kleinman A, Link BG, Phelan JC, Lee S, Good B. Culture and stigma: adding moral experience to stigma theory. Soc Sci Med. 2007 Apr;64(7):1524-35.

3 Link BG, Phelan JC. Conceptualizing stigma. Annu Rev Sociol.. 2001;27(1):363-85.

4 Corrigan PW, Watson AC. Understanding the impact of stigma on people with mental illness. World Psychiatry. 2002 Feb;1(1):16-20.

5 Scheff TJ. Being mentally ill: a sociology theory. Chicago: Aldine; 1966.
6 Link BG, Cullen FT, Struening EL, Shrout PE, Dohrenwend BP. A modified labelling theory approach to mental disorders: an empirical assessment. Am Sociol Rev. 1989 Jun;54(3): $400-23$.

7 Link BG, Struening EL, Neese-Todd S, Asmussen S, Phelan JC. Stigma as a barrier to recovery: the consequences of stigma for the self-esteem of people with mental illnesses. Psychiatr Serv. 2001 Dec;52(12): 1621-6.

8 Markovitz FE. The effects of stigma on the psychological well-being and life satisfaction of persons with mental illness. J Health Soc Beh. 1999 Dec;39(4):335-47.

9 Burton CL, Wang K, Pachankis JE. Does getting stigma under the skin make it thinner? Emotion regulation as a stress-contingent mediator of stigma and mental health. Clin Psychol Sci. 2018 Jul;6(4):590-600.

10 Link BG, Stuart H. On revisiting some origins of the stigma concept as it applies to mental illnesses. In: Gaebel W, Sartorius N, Rössler $\mathrm{W}$, editors. The stigma of mental illness: end of the story? Heidelberg New York Dordrecht London: Springer; 2017. p. 3-28.
Alienation in Social Stigmatization and Depression
Psychopathology 2022;55:201-210 DOI: $10.1159 / 000519253$ 
11 Wong A, editor. Disability visibility: first-person stories from the twentieth-first century. New York: Penguin Vintage Books; 2021.

12 Kuusisto S. Planet of the blind: a memoir. New York: Dell Publishing; 1997.

13 Lythcott-Haims J. Real American: a memoir. New York: St. Martin’s Griffin; 2017.

14 McBryde Johnson H Unspeakable conversations. In: Wong A, editors. Disability visibility: first-person stories from the twentiethfirst century. New York: Penguin Vintage Books; 2021. p. 3-27.

15 Henley A. There's a mathematical equation that proves that I'm ugly - Or so I learned in my seventh-grade art class. In: Wong A, editor. Disability visibility: first-person stories from the twentieth-first century. New York: Penguin Vintage Books; 2021. p. 39-46.

16 Jardine J, Szanto T. Empathy in the phenomenological tradition. In: Maibom HL, editor. The routledge handbook of empathy. London and New York: Routledge; 2017. p. 86-97.

17 Overgard S, Zahavi D. Phenomenological sociology: the subjectivity of everyday life. In: Jacobsen MD, editor. Encountering the everyday: an introduction to the sociologies of the unnoticed. Houdsmills. London: Palgrave McMillan; 2009. p. 93-15.

18 da Costa T Between relevance systems and typification structures: alfred schutz on habitual possessions. Ph Mind. 2016 Nov; 6:6672.

19 Taipale J. From types to tokens: empathy and typification. In: Szanto T, Moran D, editors. Phenomenology of sociality. Discovering the 'we'. London: Routledge; 2016. p. 143-58.

20 Fuchs T. Empathy, group identity, and the mechanisms of exclusion: an investigation into the limits of empathy. Topoi. 2019;38(1) 239-50.

21 Wilson B. On NYC's paratransit; fighting for safety, respect, and human dignity. In: Wong A, editor. Disability visibility: first-person stories from the twentieth-first century. New York: Penguin Vintage Books; 2021. p. 20519.

22 Woody J. The isolation of being deaf in prison. In: Wong A, editor. Disability visibility: first-person stories from the twentieth-first century. New York: Penguin Vintage Books; 2021. p. 59-62.

23 Gehring K. Time is up for me, too. In: Wong A, editor. Disability visibility: first-person stories from the twentieth-first century. New York: Penguin Vintage Books; 2021. p. 243-9.

24 Thornton SRT. We can't go back. In: Wong A, editor. Disability visibility: first-person stories from the twentieth-first century. New York: Penguin Vintage Books; 2021. p. 85-9.

25 Cubacub S. Radical visibility: a disabled queer clothing reform movement manifesto. In: Wong A, editor. Disability visibility: first-person stories from the twentieth-first century. New York: Penguin Vintage Books; 2021. p. 90-100.
26 Fuchs T. The phenomenology and development of social perspectives. Phenom Cogn Sci. 2013;12(4):655-83.

27 Zahavi D. Second-person engagement, selfalienation, and group-identification. Topoi. 2019;38(1):251-60.

28 Brown K. Nurturing black disabled joy. In: Wong A, editor. Disability visibility: first-person stories from the twentieth-first century. New York: Penguin Vintage Books; 2021. p. $117-20$.

29 Moore L. I'm tired of chasing a cure. In: Wong A, editor. Disability visibility: first-person stories from the twentieth-first century. New York: Penguin Vintage Books; 2021. p. 75-81.

30 Ho S. Canfei to Canji: the freedom of being loud. In: Wong A, editor. Disability visibility: first-person stories from the twentieth-first century. New York: Penguin Vintage Books; 2021. p. 112-6.

31 Eric-Udorie J. When you are waiting to be healed. In: Wong A, editor. Disability visibility: first-person stories from the twentiethfirst century. New York: Penguin Vintage Books; 2021. p. 53-8.

32 Slice J. Imposter syndrome and parenting with a disability. In: Wong A, editor. Disability visibility: first-person stories from the twentieth-first century. New York: Penguin Vintage Books; 2021. p. 129-33.

33 Sjunneson E. How to make a paper crane from rage. In: Wong A, editor. Disability visibility: first-person stories from the twentieth-first century. New York: Penguin Vintage Books; 2021. p. 134-40.

34 Slaby J, Röttger-Rössler B. Introduction: af fect in relation. In: Röttger-Rössler B, Slaby J, editors. Affect in relation - families, places, technologies. New York: Routledge; 2018. p. $1-27$.

35 Slaby J. Relational affect: perspectives from philosophy and cultural studies. In: van Alpen E, Jirsa T, editors. How to do things with affects: affective triggers in aesthetic forms and cultural practices. Leiden: Brill Rodopa; 2019. p. $59-81$.

36 Anderson B. Affective atmospheres. Emotion, Space Soc. 2009;2(2):77-81.

37 Slaby J. Emotions and the extended mind. In: von Scheve C, Salmela M, editors. Collective emotions. Oxford: Oxford University Press; 2014. p. 32-46.

38 Ratcliffe M. The feeling of being. J Conscious Stud. 2005;12(8-10):24-31.

39 Ratcliffe M. Feelings of being: phenomenology, psychiatry and the sense of reality. Oxford: Oxford University Press; 2008.

40 Stephan A. Emotions, existential feelings, and their regulation. Emot Rev. 2012;4(2):157-62.

41 Jacobs K, Stephan A, Paskaleva-Yankova A, Wilutzky W. Existential and atmospheric feelings in depressive comportment. Philos Psychiatry, Psychol. 2014;21(2):89-110.
42 Fuchs T. Depression, intercorporeality and interaffectivity. J Conscious Stud. 2013;20(78):219-38.

43 Paskaleva-Yankova A. A phenomenologically inspired framework of the experience of depression described in first-person testimonies: possibility, ability, and being with others in depression: 2017. Available from: https:// repositorium.ub.uni-osnabrueck.de/handle/ urn:nbn:de:gbv:700-20190108999.

44 van den Berg JH. A different existence: principles of phenomenological psychopathology. Pittsburgh: Duquesne University Press; 1972-2013.

45 Fuchs T. Pathologies of intersubjectivity in autism and schizophrenia. J Conscious Stud. 2016;22(1-2):191-14.

46 Gallagher S. Understanding interpersonal problems in autism: interaction theory as an alternative to theory of mind. Philos, Psychiatry, Psychol. 2004;11(3):199-217.

47 Gallagher S. Intersubjectivity in perception. Cont Philos Rev. 2008;41(2):163-78.

48 Gallagher S, Hutto DD. Understanding others through primary interaction and narrative practice. In: Zlatev J, Racine $\mathrm{T}$, Sinha C, Itkonen E, editors. The shared mind: perspectives on intersubjectivity. Amsterdam/Philadelphia: John Benjamins Publishing; 2008. p. 17-38.

49 Gallagher S, Zahavi D. The phenomenological mind. 2nd ed. London, New York: Routledge; 2012

50 Zahavi D. Intersubjectivity. In: Luft S, Overgaard S, editors. The routledge companion to phenomenology Online Edition; 2011. https: // www.routledgehandbooks.com/ doi/10.4324/9780203816936.ch16.

51 Hatfield J. When i grow up: a memoir. New Jersey: John Wiley and Sons Inc.; 2008.

52 Styron W. Darkness visible: a memoir of madness. London: Vintage Books; 1989.

53 Danquah N. Willow weep for me: a black woman's journey through depression. New York, London: W. W. Norton \& Company; 1998.

54 Wurtzel E. Prozac nation: young and depressed in America: a memoir. London: Quartet Books; 1995

55 Solomon A. The noonday demon: an anatomy of depression. London: Vintage Books; 2001.

56 Thompson T. The beast: a journey through depression. New York: Penguin; 1995.

57 Smith J. Where the roots reach for water: a personal and natural history of melancholia. New York: North Point Press; 1999.

58 Crafton BC. Jesus wept: when faith and depression meet. San Francisco: Jossey-Bass; 2009.

59 Lewis G. Sunbathing in the rain: a cheerful book about depression. London: Flamingo; 2002.

60 Malai-Ali R. The cow jumped over the moon the strange and extraordinary tale of a nervous breakdown. Oxford: Oneworld; 2007. 